\title{
Characterization of the Inhibition Layer on Galvanized Interstitial Free Steels
}

\author{
S. Dionne*, G. A. Botton*, M. Charest* and F. E. Goodwin** \\ * CANMET-Materials Technology Laboratory, 568 Booth St., Ottawa, Canada K1A 0G1 \\ ** ILZRO, 2525 Meridian Parkway, P.O. Box 12036, Research Triangle Park, NC 27709-2036 USA
}

Galvannealed steels have seen expanded use for automotive applications because of their superior properties over those of pure zinc coatings. During the galvannealing treatment, the iron aluminide inhibition layer that forms on the steel surface during galvanizing is broken down and interdiffusion of iron and zinc gives rise to a series of iron-zinc intermetallics. The formability and other in-service properties of galvannealed coatings are very sensitive to their composition and microstructure. Therefore, an understanding of the formation of the inhibition layer and its breakdown during the annealing treatment is required to optimize coating performance. In the present study, the microstructure of galvanized coatings produced on interstitial free steels under conditions typical of industrial continuous galvannealing (i.e. an effective $\mathrm{Al}$ content in the zinc bath of about $0.135 \%$ at $460^{\circ} \mathrm{C}$ ) was examined using a combination of advanced characterizationtechniques.

The galvanized coatings formed on Ti-, Ti-Nb- and Ti-Nb-P- IF steels were not strongly influenced by the substrate composition. All of the samples had a continuous aluminum-rich inhibition layer with $\mathrm{Al} / \mathrm{Fe}$ ratio in the $\mathrm{Fe}_{2} \mathrm{Al}_{5}$ range or above, as well as $\delta$ and $\zeta$ iron-zinc crystals with significantly higher $\mathrm{Fe}$ content (and $\mathrm{Al}$ content in the case of $\delta$ ) than predicted from equilibrium considerations (FIG. 1 to 4 ). The $\delta$ crystals were located on top of the interfacial $\mathrm{Fe}_{2} \mathrm{Al}_{5}$ inhibition layer. There was no evidence of $\mathrm{Zn}$ or $\mathrm{Al}$ diffusion in the ferrite grains or emerging grain boundaries. Mn and/or Ti oxides were observed within the inhibition layer and at the interface between the substrate and the inhibition layer (FIG. 5). These surface oxides did not affect the thickness or composition of surrounding inhibition layer phases. Surface enrichment of alloying elements such as $\mathrm{Mn}, \mathrm{Si}, \mathrm{P}$ and $\mathrm{Cr}$ has been reported by several authors [1] [2]. The phenomenon is driven by selective oxidation of the alloying elements during annealing of the strip in a low dew point atmosphere.

The microstructure of the galvanized coatings is consistent with the following sequence of phase formation during galvanizing. When the strip initially makes contact with the zinc bath, dissolution of the substrate in the bath produces an increase of the Fe content in the melt close to the strip surface. The inhibition layer then precipitates on the strip surface from this Fe-supersaturated melt. With an effective $\mathrm{Al}$ content in the zinc bath at the knee point of the Fe-Zn-Al solubility curve and industrial processing conditions, $\mathrm{Fe}_{2} \mathrm{Al}_{5}$. was the first phase to form on the strip surface. Surface oxide particles within the inhibition layer suggest that precipitation of the $\mathrm{Fe}_{2} \mathrm{Al}_{5}$ crystals was concurrent with strip dissolution or that growth of the inhibition layer towards the ferrite substrate took place. $\mathrm{Fe}_{2} \mathrm{Al}_{5}$ formation was followed by the precipitation of $\delta$ crystals. Finally, Fe-rich $\zeta$ crystals were precipitated from the supersaturated zinc overlay during the solidification of the coating.

References

[1] M. Guttman et al., Galvatech '95: The Use and Manufacture of Zinc and Zinc Alloy Coated Sheet Steel Products into the 21st Century, (Iron and Steel Society/AIME, 1995), pp. 295-307. 
[2] W. van Koesveld et al., Galvatech '95 : The Use and Manufacture of Zinc and Zinc Alloy Coated Sheet Steel Products into the 21st Century, (Iron and Steel Society/AIME, 1995), pp.343-355.

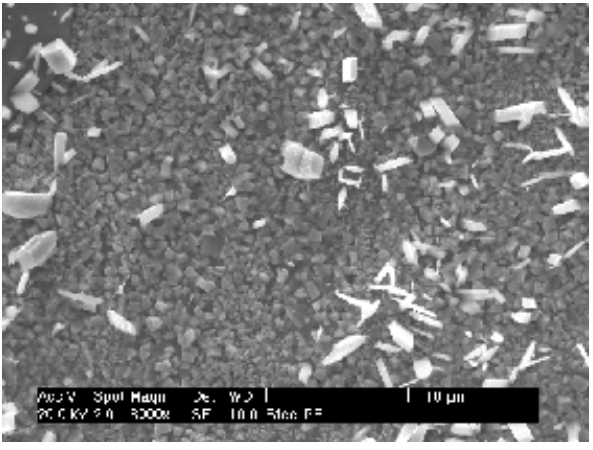

FIG. 1. SEM of a galvanized rephosphorized IF steel showing $\delta$ and $\zeta$ crystals (the zinc overlayer was removed by selective etching).

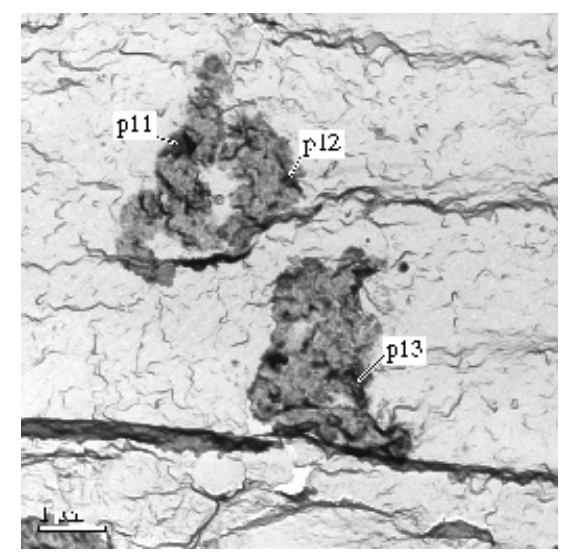

FIG. 3. TEM image of inhibition layer particles on a replica of a galvanized Ti-NbIF steel. Particle 11 was identified as $\mathrm{Fe}_{2} \mathrm{Al}_{5}$ with zone axis [0 12 ] using CBED.

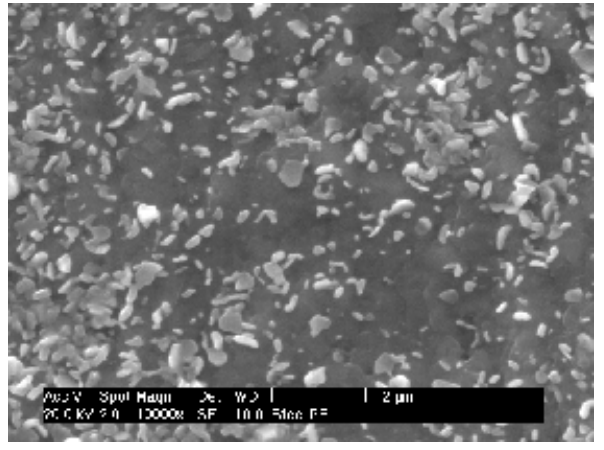

FIG. 2. SEM of a galvanized rephosphorized IF steel showing the $\delta$ and $\mathrm{Fe}_{2} \mathrm{Al}_{5}$ inhibition layer crystals $(\zeta$ crystals and $\mathrm{Zn}$ overlayer were removed by selective etching).

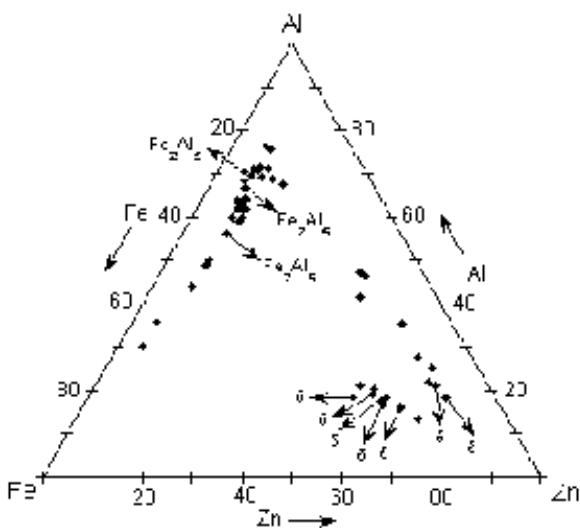

FIG. 4. Ternary plot showing the composition of inhibition layer crystals analyzed on extraction replicas prepared from a galvanized Ti-Nb-stabilized IF steel.

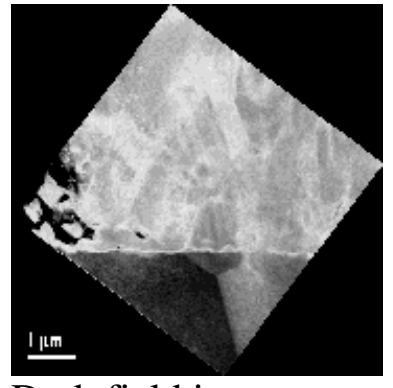

Dark field image.

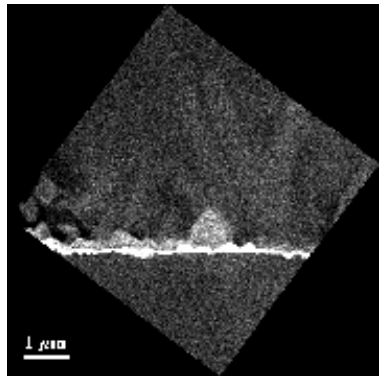

Aluminum map.

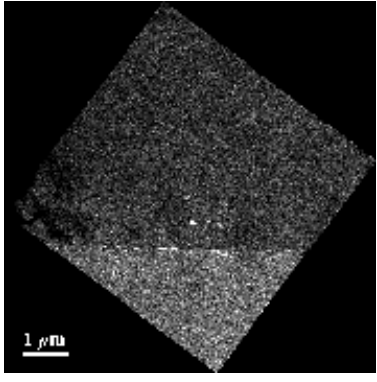

Manganese map.

FIG. 5. TEM image and elemental maps of a FIB liftout cross-section of galvanized Ti$\mathrm{Nb}-\mathrm{IF}$ steel. 